\title{
Integrated Assessment Modeling of \\ Carbon Sequestration and Land Use Emissions Using Detailed Model Results and Observations
}

Progress Report (December 2000-December-2004)

A Research Project Funded by the Department of Energy (DOE-DE-FG02-01ER63069)

Office of Biological and Environmental Research of the Office of Science

Office of the Science Financial Assistance Program Notice 00-18:

Integrated Assessment Global Climate Change Research

Principal Investigator: Atul K. Jain

University of Illinois, Urbana, IL 61801

Email: jain@atmos.uiuc.edu 


\section{Final Progress Report: December 2000-December 2004}

This report outlines the progress on the development and application of Integrated Assessment Modeling of Carbon Sequestrations and Land Use Emissions supported by the DOE Office of Biological and Environmental Research (OBER), U.S. Department of Energy, Grant No. DOE-DE-FG02-01ER63069. The overall objective of this collaborative project between the University of Illinois at Urbana-Champaign (UIUC), Oak Ridge National Laboratory (ORNL), Lawrence Livermore National Laboratory (LLNL), and Pacific Northwest National Laboratory (PNNL) was to unite the latest advances in carbon cycle research with scientifically based models and policy-related integrated assessment tools that incorporate computationally efficient representations of the latest knowledge concerning science and emission trajectories, and their policy implications.

As part of this research we accomplished the following tasks that we originally proposed:

- In coordination with LLNL and ORNL, we enhanced the Integrated Science Assessment Model's (ISAM) parametric representation of the ocean and terrestrial carbon cycles that better represent spatial and seasonal variations, which are important to study the mechanisms that influence carbon sequestration in the ocean and terrestrial ecosystems.

- Using the MiniCAM modeling capability, we revised the SRES (IPCC Special Report on Emission Scenarios; IPCC, 2000) land use emission scenarios

- On the application front, the enhanced version of ISAM modeling capability is applied to understand how short- and long-term natural carbon fluxes, carbon sequestration, and human emissions contribute to the net global emissions (concentrations) trajectories required to reach various concentration (emission) targets.

Under this grant, 21 research publications were produced. In addition, this grant supported a number of graduate and undergraduate students whose fundamental research was to learn a disciplinary field in climate change (e.g., ecological dynamics and ocean circulations) and then complete research on how this field could be linked to the other factors we need to consider in its dynamics (e.g., land use, ocean and terrestrial carbon sequestration and climate change).

Moreover, under the collaboration between the University of Illinois at UrbanaChampaign (UIUC), Oak Ridge National Laboratory (ORNL), Lawrence Livermore National Laboratory (LLNL), and Pacific Northwest National Laboratory (PNNL), two graduate students and one undergraduate student supported by this grant visited various national laboratories (LLNL, PNNL, and ORNL) during the summer of 2003 and 2004 to work with scientists there and gain additional understanding of the emerging field of ocean and terrestrial carbon sequestration.

In the following, the significant findings from the DOE supported studies are outlined. 


\section{Ocean Carbon Cycle Model: Development and Implementation for the Carbon Sequestration Studies.}

Using high-resolution, process-level climate and carbon cycle models together with observational data, we developed and implemented regional and seasonal three basin coupled climate-carbon ocean model for the ocean carbon sequestration studies. The multi-basin ocean model resolves the Atlantic, Pacific and Indian Ocean separately. This improved representation accounts for physical transport processes, chemical equilibrium, and biological reactions that govern the oceanic distributions of inorganic and organic carbon, alkalinity, and phosphate as well the climate ocean carbon cycle feedbacks important for the carbon sequestration studies (Cao and Jain, 2005a,b).

The model has been used to examine possible feedbacks between global climate change and the ocean carbon cycle system. The most important finding of this study is that projected warming over the next century can decrease the strength of oceanic $\mathrm{CO}_{2}$ uptake. This results in lower emissions being required for a given $\mathrm{CO}_{2}$ stabilization pathway relative to emissions calculated in the absence of climate feedbacks. By 2100, the cumulative emissions calculated with climate \& carbon cycle feedbacks are $9 \%$ lower than for the no-feedback case for both the WRE550 and WRE1000 $\mathrm{CO}_{2}$ pathways (Jain et al., 2001).

In other study the model has been applied to study the effectiveness of ocean carbon sequestration by direct injection at different locations and ocean depths under the sequestration scenarios described in the OCMIP. Our results indicate that in general, injections into the Pacific Ocean are more effective than injection at the same depth in the Atlantic Ocean. The results were compared with those of 3-D AOGCM experiments. The AOGCM results indicate that in general, injection into the Pacific Ocean is more effective than injection at the same depth in the Atlantic Ocean. However, ISAM results show that climate change has much larger effect on direct carbon injection in the Atlantic Ocean than in the Pacific and Indian Ocean. As a result, under climate change the Atlantic Ocean could ultimately hold more injected carbon than Pacific and Indian Oceans. (Cao and Jain, 2002; Jain and Cao, 2005).

\section{The Sensitivity of Oceanic Carbon Uptake and Circulation to the Rate of $\mathrm{CO}_{2}$ Increase} and Climate Change and Hydrological Cycle

In this study, we investigated an important feedback loop in the climate-carbon cycle system that involves increases in atmospheric $\mathrm{CO}_{2}$ and the resulting changes in temperature, the hydrological cycle, ocean circulation, and oceanic carbon uptake. This study was conducted using the advanced version of ISAM. This version of the model has the ability to successfully simulate regional and seasonal historical and current climates, the ocean thermohaline circulation (THC), oceanic carbon uptake, and bomb ${ }^{14} \mathrm{C}$ (Cao and Jain, 2005b).

Using a variety of $\mathrm{CO}_{2}$ increase scenarios (e.g., $0.5 \%, 1 \%, 2 \% / \mathrm{yr} \mathrm{CO}_{2}$ increase from present concentration to the level of doubling or quadrupling of $\mathrm{CO}_{2}$ ), we built upon previous studies by assessing the effect of the rate of $\mathrm{CO}_{2}$ increase, temperature, and 
hydrological cycle not only on the THC but also on the oceanic carbon uptake. We also explored the threshold values of the rate of $\mathrm{CO} 2$ increase and the absolute amount of atmospheric CO2 that are likely to induce the collapse of the North Atlantic Deep Water (NADW) formation (Cao and Jain, 2003).

\section{Measuring Ocean Carbon Sequestration Efficiency: The Role of Boundary Conditions} The accumulation of anthropogenic $\mathrm{CO}_{2}$ in the atmosphere could be slowed or even reversed with intentional storage of $\mathrm{CO}_{2}$ in the ocean. In one class of ocean storage schemes, $\mathrm{CO}_{2}$ is captured from a point source on land, pressurized to form a liquid, and then injected into the ocean interior. Contrasting claims have been made regarding the effectiveness of this approach. Some claim that most of the added $\mathrm{CO}_{2}$ would reside in the oceans for millenia; others claim that most of the added $\mathrm{CO}_{2}$ would leak back to the atmosphere within centuries. In this study, we show that these contrasting claims are the consequence of the choice of atmospheric boundary condition for ocean sequestration simulations. We used ISAM model for a more detailed analysis of the role of different boundary conditions. Our ISAM model results suggest that a responsive atmospheric $\mathrm{CO} 2$ boundary condition is appropriate for predicting future carbon concentrations, but a specified atmospheric $\mathrm{CO}_{2}$ boundary condition is appropriate for evaluating how much $\mathrm{CO}_{2}$ storage should be attributed to an ocean storage scheme (Mueller et al., 2004).

\section{Developing Carbon Management Response (CMR) Curves}

Measurement of the change in soil carbon that accompanies a change in land use (e.g., forest to agriculture) or management (e.g., conventional tillage to no-till) can be complex and expensive, may require reference plots, and is subject to the variability of statistical sampling and short term variability in weather. In this study we developed Carbon Management Response (CMR) curves that could be used as an alternative to in situ measurements. The CMR curves developed here are based on quantitative reviews of existing global analyses and field observations of changes in soil carbon. The curves show mean annual rates of soil carbon change, estimated time to maximum rates of change, and estimated time to a new soil carbon steady state following the initial change in management. We illustrate how CMR curves could be used in a carbon accounting framework while effectively addressing a number of potential policy issues commonly associated with carbon accounting. We find that CMR curves provide a transparent means to account for changes in soil carbon accumulation and loss rates over time, and also provide empirical relationships that might be used in the development or validation of ecological or Earth system models. This research produced two Journal articles (West and Post 2002; West et al., 2004).

\section{Terrestrial Biosphere Model: Development and Implementation for the Carbon Sequestration Studies}

A terrestrial carbon cycle component of the Integrated Science Assessment Model (ISAM) is extended and used to examine the response of plant and soil carbon stocks to historical changes in land cover, land use management, atmospheric CO2 concentration and climate. This geographically-explicit implementation of ISAM simulates the carbon fluxes to and from different compartments of the terrestrial biosphere with 0.5 -by- 0.5 degree spatial resolution (longitude and latitude). Each grid cell contains thirteen land 
coverage classifications, which represent both highly managed land uses and less managed biomes. Changes in areas between land cover classifications are driven by land uses that have resulted in, e.g., shifting-agriculture, afforestation, deforestation, and reforestation. Within each grid cell and land-coverage classification, the modeled carbon cycle includes feedback processes such as CO2 fertilization and temperature effects on photosynthesis, and respiration. Plant and soil carbon stocks for land-coverage classifications are also influenced by agriculture and forest management practices including, e.g., soil amendments and tillage. For the historical time period (1765 through 1990), CO2 sources and sinks are derived using the observed temperature change and $\mathrm{CO} 2$ concentrations along with surveys of past land cover change and shifts in management practices. After 1990, carbon fluxes are estimated based on the AOGCM based temperature distributions and ISAM based CO2 concentrations. (Jain and Kheshgi, 2002, Jain and Yang, 2005).

More recently, we assimilated the CMR curves developed based on various sequestration strategies into the Integrated Science Assessment Model (ISAM) to study the global potential to sequester carbon in soils. For this study sequestration strategies were chosen that have a significant potential to sequester carbon in soil. In agricultural systems, practices included a change from conventional tillage to no-till, an increase in rotation complexity, use of organic fertilizers, and application of irrigation water. The sequestration rates associated with agricultural sequestration options were combined to represent a "general" category for agricultural sequestration. Grassland management to sequester soil carbon included irrigation, earthworm introduction, improved grass species, introduction of legumes, improved grazing, and fertilization. Data used in estimates for agricultural and grassland management sequestrations are from West et al. (2003). On the global scale, ISAM model results show that agriculture and grassland management practices have a potential to store additional up to $56 \mathrm{GtC}$ of carbon in soil over the next 40 years and $40 \mathrm{GtC}$ over next 60 years. The results of this study will be presented at the $7^{\text {th }}$ International Carbon Cycle Conference to be held in Boulder, CO, Sept. 25-30, 2005.

\section{Quantifying the Uncertainties in the Carbon Content of the Terrestrial Biosphere} According to the IPCC (2001), all major terms in 1980s estimates of the global carbon budget are subject to uncertainties. However, uncertainties in land use changes and terrestrial sinks are the largest, at up to 200\%. In this study we quantified the uncertainties in regional land use emissions as well as net terrestrial flux over the period 1765-2000. Using the terrestrial carbon cycle component of the Integrated Science Assessment Model (ISAM) coupled with observed atmospheric CO2, temperature and precipitation data, the effects of different land cover data sets on the response of plant and soil carbon stocks were assessed. ISAM model simulations indicated that uncertainties in net terrestrial fluxes during the 1980s is mainly due to the large uncertainties in land cover change data for tropical Africa and south and south east Asia (Jain and Yang, 2003).

\section{Projecting Future Climate Change: Implications of Carbon Cycle Model Inter- Comparisons}


The range of responses of alternate detailed models for the ocean and biosphere components of the global carbon cycle, catalogued in model intercomparison studies, are simulated by a ISAM employing a range of model parameters. We used ISAM to construct ranges of: 1) past carbon budgets given past $\mathrm{CO}_{2}$ concentrations, fossil carbon emissions, and temperature records, 2) future $\mathrm{CO}_{2}$ concentrations and temperature for given emission scenarios, and 3) $\mathrm{CO}_{2}$ emissions and temperature for given trajectories of future $\mathrm{CO}_{2}$ concentrations leading to constant levels within the next several centuries. Carbon cycle is an additional contributor to uncertainty in climate projections that is calculated to expand the range of projected global temperature beyond that assessed by the Intergovernmental Panel on Climate Change (IPCC). The results of this study have been published in Global Biogeochemical Cycles (Kheshgi and Jain, 2003).

\section{Climate Sensitivity Uncertainty and the Need for Non-CO ${ }_{2}$-Emitting Energy Sources}

The UN Framework Convention on Climate Change calls for "stabilization of greenhouse gas concentrations at a level that would prevent dangerous anthropogenic interference with the climate system." Even if we could determine a "safe" level of interference in the climate system, the sensitivity of global mean temperature to increasing atmospheric $\mathrm{CO}_{2}$ is known perhaps only to a factor of three or worse. Using ISAM, we show that uncertainty in climate sensitivity introduces a factor of eight or more uncertainty in allowable $\mathrm{CO}_{2}$ concentrations and even greater uncertainty in allowable $\mathrm{CO}_{2}$ emissions. Nevertheless, unless climate sensitivity is low and acceptable amounts of climate change are high, climate stabilization will require a massive transition to carbon-emission-free energy technologies. The results of this study were published in Science (Caldeira, Jain et al., 2003).

\section{Advanced Technology Paths to Global Climate Stability: Energy for a Greenhouse Planet}

Stabilizing climate is an energy problem. To establish a course toward climate stabilization will require the development within the coming decades of new primary energy sources that do not emit carbon dioxide to the atmosphere, in addition to efforts to reduce end-use energy demand. Here we survey possible future energy sources, evaluated for both their capability to supply massive amounts of carbon-emissions-free energy required and their potential for large-scale commercialization. Possible candidates for primary energy sources include terrestrial solar and wind energy, solar power satellites, biomass, nuclear fission, nuclear fusion, fission-fusion hybrids, and fossil fuels from which carbon has been sequestered. Non-primary-power technologies that could contribute to climate stabilization include efficiency improvements, hydrogen production, storage and transport, superconducting global electric grids, and geoengineering. All of these approaches currently have severe deficiencies that limit their ability to stabilize global climate. We conclude that a broad range of intensive research and development is urgently needed to produce technological options that can allow both climate stabilization and economic development. The results of this study were published in Nature (Hoffert et al., 2002).

\section{Book Chapter on the Evaluation of the Latest Scientific Understanding of Stratospheric Ozone Depletion and Enhanced Greenhouse Warming}


There is wide consensus within the scientific community that the two major issues in global change -stratospheric ozone depletion and enhanced greenhouse warming - have been caused by human-related increases in greenhouse gases in the Earth's atmosphere. This book chapter evaluates the latest scientific understanding of these two problems, historical, current and future trends in greenhouse gas concentrations, their potential impacts, and current policy considerations (Jain and Hayhoe, 2002).

\section{Interactive Computer Tool for the Integrated Assessment of Climate Change}

A web interface has been further developed for a simplified version of our Integrated Science Assessment Model (ISAM) (http://isam.atmos.uiuc.edu/isam). The interface has been designed for use as an educational tool and includes user-friendly features such as a tutorial, background information, and graphing applications. The goals of this web interface are to introduce non-specialist users, such as students, researchers from other disciplines and policymakers, to a climate modeling system; to allow these users to test hypotheses, develop scenarios, and learn about the implications of changing various components of the modeled system; and to permit a non-specialist to evaluate key factors in the global warming debate, such as the outcome of any specified emission scenario or the sensitivity of the model to physical parameters. The ISAM web interface has been tested in three courses at the University of Illinois (ATMOS 140, 345, 397) as well as at a number of other U.S. and European universities.

\section{Research papers that have been sponsored completely or in part by DOE/OBER program.}

\section{Journal Articles}

Calderia, K, A. Jain, M. Hoffert, 2003: Energy implications of uncertainty in climate sensitivity to increased atmospheric CO2 concentration, Science, 299, 2052-2054.

Cao L., and A.K. Jain, 2005a: An Earth System Model of Intermediate Complexity: ISAM-2.5D: part 1: description of climate component and the role of ocean mixing parameterizations in simulated climate, J.Geophys. Res.- Ocean (submitted).

Cao L., and A.K. Jain, 2005b: An Earth System Model of Intermediate Complexity: ISAM-2.5D: part 2: description of carbon cycle component and the role of ocean mixing parameterizations in simulated uptake for natural and bomb radiocarbon and anthropogenic $\mathrm{CO}_{2}$, J.Geophys. Res.- Ocean, (submitted).

Hoffert, M.I, K. Caldeira, G. Benford, D. R. Criswell, C. Green, H. Herzog, A. K. Jain, H. S. Kheshgi, K. S. Lackner, J. S. Lewis, H. D. Lightfoot, W. Manheimer, J.C. Mankins, G. Marland, M. E. Mauel, L. John Perkins, M.E. Schlesinger, T. Volk, T. M.L. Wigley, 2002: Advanced Technology Paths to Global Climate Stability: Energy for a Greenhouse Planet, Science 298, 981-987 (review article).

Hoffert, M.I, K. Caldeira, G. Benford, D. R. Criswell, C. Green, H. Herzog, A. K. Jain, H. S. Kheshgi, K. S. Lackner, J. S. Lewis, H. D. Lightfoot, W. Manheimer, J.C. Mankins, G. Marland, M. E. Mauel, L. John Perkins, M.E. Schlesinger, T. Volk, T. M.L. Wigley, 2002: Planning for future energy resources, Science , 300, 581-584 (Letter to Editor). 
Jain, A. K. and L. Cao, 2005: Assessing the effectiveness of direct injection for ocean carbon sequestration under the influence of climate change, Geophysical Research Letters (in press).

Jain, A.K. and X. Yang (2005): Modeling the Effects of Two Different Land Cover Change Data Sets on the Carbon Stocks of Plants and Soils in Concert With CO2 and Climate Change, Global Biogeochemical Cycles (in press).

Kheshgi, H.S., and A.K. Jain, 2003: Projecting future climate change: Implications of carbon cycle model intercomparision, Global Biogeochemical Cycles, 17(2), 1047, doi:10.1029/2001GB001842..

Mueller, K., L. Cao, K. Caldeira, and A. K. Jain, 2004: Differing methods of accounting ocean carbon sequestration efficiency, Journal of Geophysical Research-Ocean), 109, C12018, doi:10.1029/2003JC002252.

West, T.O. and W.M. Post. 2002: Soil organic carbon sequestration rates by tillage and crop rotation: A global analysis, Soil Science Society of America Journal, 66, 19301946.

West, T, G. Marland, A. W. King, W. M. Post, A. K. Jain, and K. Andrasko, 2004: Carbon management response curves: Estimates of Temporal soil carbon dynamics, Environmental Management, 33(4), 507-518.

\section{Book Chapter}

Jain, A.K., K.A.S. Hayhoe, 2001, Global air pollution problems, In Handbook of Atmospheric Sciences, Vol.2: Problems, Tools and Applications, C. N. Hewitt and A. V. Jackson (eds.), Blackwell Science Ltd, Oxford, UK, pp 339- 371, Blackwell Science., Malden, Mass.

\section{Articles in Conference Proceedings}

Cao, L. and A.K. Jain, 2002: Modeling the Combined Effects of CO2, Climate and Land Use on the Carbon Stocks of Plants and Soils, Eos. Trans. AGU, 82347). Fall Meet. Suppl.

Cao, L. and A.K. Jain, 2003: The sensitivity of oceanic carbon uptake and circulation to the rate of $\mathrm{CO}_{2}$ increase and climate change and hydrological cycle, Accepted for presentation at the 2003 AGU Fall Meeting, to be held in San Francisco, December 8-12, 2003.

Jain, A.K., L. Cao, K. Caldeira, H.S. Kheshgi, 2001: The Simulated Influence of Anthropogenic Climate Warming on the Oceanic Carbon Cycle, Eos. Trans. AGU, 82(47), Fall Meet. Suppl., Abstract OS11C-0384.

Jain, A.K., 2001: The carbon cycle and stabilization of atmospheric CO2, Proceedings of the IPIECA (Intl Petroleum Industry Environmental Conservation Association) Symposium on Long Term Carbon and Energy Management, Cambridge, MA, Oct 15-16, 2001.

Jain, A. K., 2003: The Carbon Cycle and Stabilization of Atmospheric $\mathrm{CO}_{2}$, Intl. Conference on Climate Change and Environmental Policy, University of Illinois @ Urbana-Champaign, Nov 11-12 (Invited Talk), 2002.

Jain, A. K. and X. Yang, 2003: Quantifying the uncertainties in the carbon content of the terrestrial biosphere, Accepted for presentation at the 2003 AGU Fall Meeting, to be held in San Francisco, December 8-12, 2003. 
Jain, A. K., X. Yang, T. West, and W. Post, 2005: Assessing the Effectiveness of Carbon Sequestration in North America Soil and its Impact on Net Terrestrial Uptake of CO2, Presented at the $7^{\text {th }}$ International Carbon Cycle Meeting, Boulder, CO, Sept. 25-30, 2005.

Kheshgi, H.S., A.K. Jain, 2003: Projecting Future Climate Change: Implications of Carbon Cycle Model Intercomparisons, International Symposium on Climate Change (ISCC), Beijing, China, March 31-April 3, 2003.

Jain, A. K. and X. Yang, 2003: Quantifying the uncertainties in the carbon content of the terrestrial biosphere, Accepted for presentation at the 2003 AGU Fall Meeting, to be held in San Francisco, December 8-12, 2003. 